\title{
A newly diagnosed South African case of congenital erythropoietic porphyria
}

\section{Sweta Das, Ozge Gunduz, Zateen Modi, Deepak Modi}

\author{
Division of Dermatology, Faculty of Health Sciences, University of the Witwatersrand, Johannesburg, Gauteng, South Africa
}

Corresponding author: Dr. Deepak Modi, E-mail: profmodi@gmail.com

\begin{abstract}
Congenital Erythropoietic Porphyria (CEP) is a rare disease due to the marked deficiency of uroporphyrinogen III synthase (UROS) enzyme, which leads to the accumulation of uroporphyrin 1 and coproporphyrin 1 isomers. We report a 3-year-old girl presenting with a one-year history of sun induced blistering skin lesions born to a HIV-positive mother in South Africa. She had systemic disease as evidenced by a severe hemolytic anemia and splenomegaly. The biochemical fraction analysis of porphyrines in urine and stool samples confirmed our clinical diagnosis. The UROS enzyme defect in red blood cells and fibroblast can be cured via stem cell transplantation. Our patient is on the waiting list for bone marrow transplant. CEP has a multisystemic involvement including cutaneous, ocular, skeletal and hematological complications, requiring a multidisciplinary management approach.
\end{abstract}

Key words: Congenital erythropoietic porphyria; Stem cell transplantation; Children; Skin

\section{INTRODUCTION}

Congenital Erythropoietic Porphyria (CEP), also named as Günther's disease, is an extremely rare condition. There have been approximately 300 cases reported in the English literature. CEP has no racial predilection and occurs equally in both genders. It has a broad range in age (median 1.75 years, from 30 weeks' gestation to 40 years), manifestations and varying severity at the onset of the disease [1]. A marked deficiency of uroporphyrinogen III synthase (UROS) enzyme leads to the accumulation of uroporphyrin 1 and coproporphyrin 1 isomers in all tissues of the body [2]. The genetic defect is most commonly in the gene encoding UROS enzyme in an autosomal recessive manner, and rarely in the GATAl gene as an X-linked manner. CF3R mutation of the UROS gene is accounting for $20 \%$ of the reported mutations in CEP [3].

\section{CASE REPORT}

A 3-year-old girl was brought to the Dermatology Outpatient Clinic with a one year history of blistering skin lesions on the sun exposed areas of her face ear lobes and dorsum of her both hands mostly following sun exposure. She was the only child and there was no one in her family with a similar skin condition. She was HIV exposed but was tested negative at birth, 6 weeks, 10 weeks and lastly 6 weeks after stopping 6 months of breastfeeding, therefore received prophylactic nevirapine treatment.

Her clinical features included hypertrichosis of her cheeks, erosions and scarring on her face, ear lobes and dorsum of her both hands, and a few intact vesicles located on her hands (Fig. 1). Her teeth showed a reddish brown discoloration (Fig. 2). Abdominal examination revealed significant splenomegaly. Her urine was red in color, and microscopic examination excluded hematuria. The clinical presentation suggested the diagnosis of CEP which was additionally supported by orange red fluorescence of her teeth and urine under Wood's lamp examination (Fig. 3). Histopathological examination of an intact blister revealed a large cellpoor subepidermal blister, festooning of dermal papillae into the blister cavity base, and superficial, thick walled sized vessels with PAS positive material within the

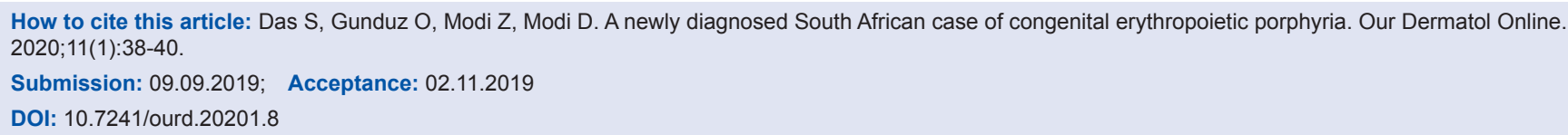




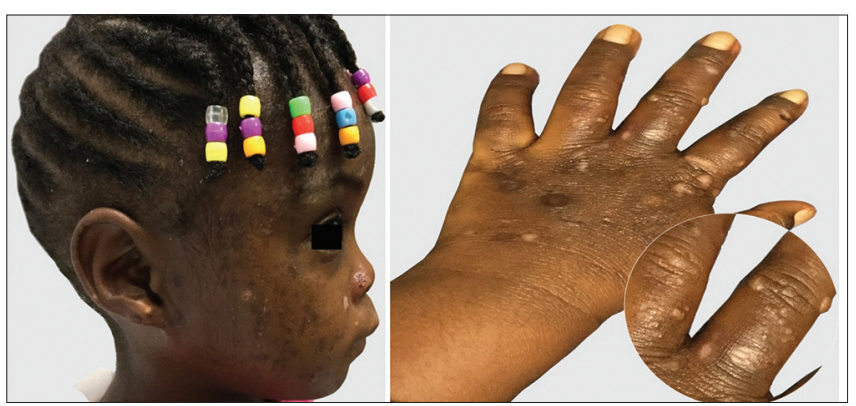

Figure 1: Hypertrichosis, erosions and scarring on the face. Scarring and an intact vesicle located on her hand.

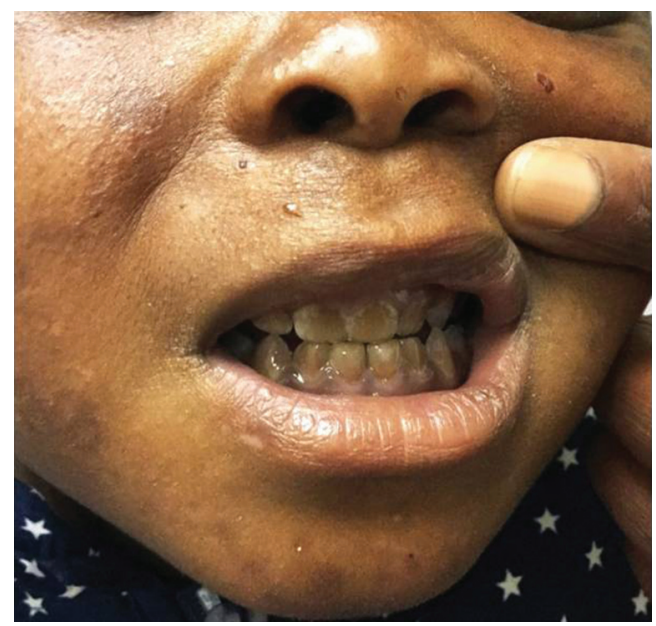

Figure 2: Erythrodontia.

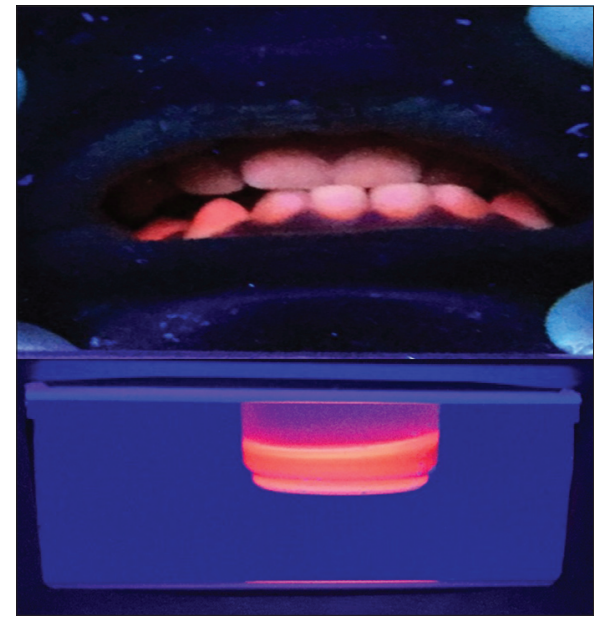

Figure 3: Wood's lamp examination showing orange red florescence of her teeth and urine.

vessel wall. Immunofluorescence revealed a positive $\mathrm{C} 3$ and $\lg \mathrm{G}$ staining at the dermoepidermal junction and in the blood vessel walls.

Urine analysis showed markedly raised porphyrin level (100617.4 nmol/L). Fraction analysis revealed raised uroporphrin $(+++)$ and coproporphyrin $(+)$. Stool analysis showed raised porphyrin level (7096 nmol/gm). Fraction analysis revealed raised protoporphyrin $(+)$, uroporphrin $(+)$ and coproporphyrin $(+++)$. Isocoproporphrin in stool which is diagnostic for porphyria cutanea tarda was undetected. During acute intermittent porphyria attacks urinary porphobilinogen and $\delta$-aminolevulinic acid excretion is high with normal faecal porphyrin levels, which were normal in our case. The biochemical fraction analysis supported our clinical diagnosis of CEP. She had no polycythemia, but she had a significant hemolytic anaemia (Hb:12.0 gr/dL, Direct Coomb's Test +, LDH:742 U/L). Serological investigations for liver and renal function tests, vitamin $\mathrm{D}$ and calcium levels were unremarkable. Hepatitis markers (HptA Ag, $\mathrm{HptB} \mathrm{Ag}, \mathrm{HptC} \mathrm{Ag}$ ) and HIV were negative. The history, clinical presentation, urine and stool investigations and biochemistry confirmed the diagnosis of CEP.

The mother was informed about the photoprotective measures, the limited management options and the prognosis of the disease. The patient was HLA typed for a bone marrow transplantation, and she is currently on the waiting list.

\section{DISCUSSION}

Cutaneous photosensitivity, blistering eruptions and increased fragility of the sun exposed skin are early cutaneous manifestation of CEP. The appearance of reddish colored urine on diapers is the first manifestation at birth. Secondary infections could cause scarring and may lead to severe deformity and disfigurement. Hypertrichosis may be seen in some patients [4]. Haemolytic anemia and splenomegaly are manifestations of systemic involvement, whereas the onset of haematological manifestations by the age of 5 is reported to be a poor prognostic indicator [1]. Deposition of porphyrin in the eye may lead to corneal ulcers, scarring and eventually to blindness [5]. Porphyrin deposits in bone lead to osteopenia, osteoporosis and increased risk in the tendency of spontaneous fractures. Additionally, vitamin D deficiency from prolonged periods of sun avoidance needs to be monitored [6].

Patient education and sun avoidance is crucial in the management of the disease. Blood transfusion and splenectomy can be considered in patients with severe hemolytic anaemia [2].

The UROS enzyme defect can be cured via stem cell transplantation (SCT) (including bone marrow and umbilical cord transplants) by replacing the defective 
enzyme in bone marrow erythroblasts, which makes the SCT the only known cure available for this disease. SCT was used first time in 1991, and since then there has been approximately 24 patients successfully treated with SCT due to CEP. SCT spectacularly improves cutaneous and systematic manifestations of CEP; however the treatment is associated with mortality due to severe complications (i.e. infections) and requires long term outcome studies [7].

CEP is a rare disease with multisystemic involvement requiring a multidisciplinary management approach.

\section{Consent}

The examination of the patient was conducted according to the Declaration of Helsinki principles.

\section{REFERENCES}

1. Katugampola RP, Badminton MN, Finlay AY, Whatley S, Woolf J, Mason N, et al. Congenital erythropoietic porphyria: a singleobserver clinical study of 29 cases. Br J Dermatol. 2012;167:901.
2. Desnick RJ, Astrin KH. Congenital erythropoietic porphyria: advances in pathogenesis and treatment. Br J Haematol. 2002;117:779-95.

3. Ben Bdira F, Gonzalez E, Pluta P, Laín A, Sanz-Parra A, FalconPerez JM, et al. Turning intracellular homeostasis of human uroporphyrinogen III synthase by enzyme engineering at a single hotspot of congenital erythropoietic porphyria. Hum Mol Genet. 2014;23:5805-13.

4. Wenner C, Neumann NJ, Frank J. Congenital erythropoietic porphyria: An update. Hautarzt. 2016;67:216-20.

5. Arné JL, Depeyre C, Lesueur L. Corneoscleral involvement in congenital erythropoietic porphyria. Günther disease. J Fr Ophtalmol. 2003;26:498-502.

6. Katugampola RP, Anstey AV, Finlay AY, Whatley S, Woolf J, Mason $\mathrm{N}$, et al. A management algorithm for congenital erythropoietic porphyria derived from a study of 29 cases. Br J Dermatol. 2012;167:888-900.

7. Peinado CM, Heredia CD, To-Figueras J, Arias-Santiago S, Nogueras P, Elorza I, et al. Successful treatment of congenital erythopoietic porphyria using matched unrelated hematopoietic stem cell transplantation. Ped Derm. 2013;30:484-9.

Copyright by Sweta Das, et al. This is an open-access article distributed under the terms of the Creative Commons Attribution License, which permits unrestricted use, distribution, and reproduction in any medium, provided the original author and source are credited.

Source of Support: Nil, Conflict of Interest: None declared. 